\title{
Attachment-Based Family Therapy for Suicidal Lesbian, Gay, and Bisexual Adolescents: A Case Study
}

\author{
Suzanne A. Levy'*, Jody Russon', and Gary M. Diamond ${ }^{2 *}$ \\ I Center for Family Intervention Science, Drexel University, Philadelphia \\ 2 Ben-Gurion University, Be'er Sheva
}

\begin{abstract}
The majority of sexual minority adolescents are well-adjusted and healthy, however, on average, $28 \%$ report suicidal ideation and between 15\% and 40\% make a suicide attempt each year. These rates are two to seven times higher than those found among heterosexual youths. Research has shown the protective function of parental support and acceptance, as well as the deleterious effects of parental criticism, invalidation, and rejection on the mental health of sexual minority adolescents. Given these risk and protective factors, these adolescents might benefit from an intervention that targets family relationships. Toward this goal, Attachment-Based Family Therapy $(A B F T)$ specifically aims to improve the quality of adolescent-parent relationships. In prior treatment developmental work, ABFT was adapted and pilot tested for depressed and suicidal lesbian, gay, and bisexual (LGB) adolescents. By adopting an evidence-based case study format, this paper provides a case summary to illustrate how the therapy was conducted. The case study consists of a vignette, followed by therapy task descriptions and illustrative transcripts. Examples of key therapeutic moments in ABFT, for depressed and suicidal LGB adolescents, are discussed in the context of the case.
\end{abstract}

Keywords: adolescents, LGB, Attachment-Based Family Therapy, case study, suicide, depression

\footnotetext{
Key Points

Lesbian, gay, and bisexual (LGB) adolescents are at a higher risk of suicidal ideation and attempting suicide compared to their heterosexual peers.

2 Parental criticism, invalidation, and rejecting messages toward LGB identities can negate protective mechanisms associated with parental support.

3 A case study is used to illustrate the adaptations made to Attachment-Based Family Therapy (ABFT) for use with LGB suicidal youth and their families.

4 ABFT for LGB youth involves identifying how destructive emotions and behaviours associated with parental non-acceptance have compromised the parent-child relationship and the child's wellbeing, and then helping the family address and resolve these issues.
}

Lesbian, gay, and bisexual (LGB) youth are particularly at risk for reporting suicidal ideation and making suicide attempts compared to their heterosexual peers (Haas et al., 2011). While the majority of sexual minority adolescents are well-adjusted and healthy (Savin-Williams, 2006), approximately $28 \%$ of these youths report symptoms of suicidality (defined as ideation, plans or intent, and attempts; Marshal et al.,

*Address for correspondence: Suzanne A. Levy, Ph.D., Center for Family Intervention Science, Drexel University, 3020 Market St., Suite 510, Philadelphia, PA 19104, USA. slevy@drexel.edu Gary M. Diamond, Ph.D., Dept. of Psychology, Ben-Gurion University of the Negev, P.O.B. 653, Beer-Sheva, Israel. gdiamond@bgu.ac.il 
2011). Furthermore, between $15 \%$ and $40 \%$ make a suicide attempt each year - rates which are two to seven times higher than their heterosexual counterparts (Haas et al., 2011). Most researchers and clinicians agree that there is nothing inherently suicidal about a same-gender sexual orientation. Instead, it is likely that negative environmental responses such as discrimination, victimisation, and rejection lead to social isolation, anxiety, low self-esteem, depression, hopelessness, and helplessness, which, in turn, lead LGB adolescents to contemplate killing themselves (Savin-Williams \& Ream, 2003).

One prominent risk factor for these youth is parental rejection of their sexual orientation. Research on LGB adolescents suggests that over half of parents initially react to their child's disclosure with some degree of negativity (D'Augelli, Grossman, Starks, \& Sinclair, 2010; Heatherington \& Lavner, 2008; Samarova, Shilo, \& Diamond, 2014), exhibiting disappointment, anger, shock, and/or guilt (Robinson, Walters, \& Skeen, 1989). In some cases, parents may deny or explicitly disapprove of their child's same-sex attractions, humiliate, threaten, or even physically attack their child, as well as eject their child from the home (Hammelman, 1993; Hunter \& Schaecher, 1987; Savin-Williams, 1989, 1994). In other instances, disapproval and invalidation may be subtler and expressed via unconscious or unintentional communications. Such subtle disapproving comments, facial expressions, or behaviours have been termed 'micro aggressions' (Nadal et al., 2011; Sue et al., 2007).

Parental criticism, invalidation, and rejection of a child's sexual orientation negatively impact the adolescent in two ways. First, such messages from parents directly convey that something is wrong with the adolescent (Goldfried \& Goldfried, 2001), increasing the likelihood that the child will perceive him/herself as bad, shameful, or unlovable (Rohner, 2014). Second, parental rejection leaves adolescents without a supportive attachment figure to turn to when they face LGB-related discrimination, victimisation, and rejection from others, further putting them at risk for suicidal ideation and behaviour.

In contrast, when parents accept their LGB adolescent, the adolescent is likely to feel validated, safe, and secure. In the context of such relationships, parents are positioned to support, guide, and advocate for their child as he or she faces the challenges of growing up with a minority sexual orientation. This is important, as parental support has been shown to moderate the negative effects of gay-related victimisation (Evans, Hawton, \& Rodham, 2004; Shilo, Antebi, \& Mor, 2015). Indeed, LGB young adults who reported that they came from highly accepting families were less likely to have suicidal thoughts. They were also less likely to have made a suicide attempt, and more likely to report higher self-esteem, social support, and general health than their LGB peers who reported low acceptance from their families (Ryan et al., 2010). Other studies suggest that the association between LGB orientation and suicidal thoughts is at least partially mediated by parental support and connectedness (Eisenberg \& Resnick, 2006; Needham \& Austin, 2010).

Given the deleterious effects of parental criticism, invalidation, and rejection, and the protective function of parental support and acceptance in the lives of sexual minority adolescents, Attachment-Based Family Therapy (ABFT) (Diamond, Diamond, \& Levy, 2014) is considered well suited to treat this population. In prior treatment development work, Diamond et al. (2012) treated 10 suicidal and depressed LGB adolescents who were living at home and were out of the closet. Adolescents 
were recruited based on their sexual orientation and high levels of suicidal and depressive symptoms. Inclusion was not based on degree of parental rejection; consequently, the degree of parental rejection varied from case to case. The authors found that, for those parents having a hard time accepting their child's sexual orientation, therapists needed to take more time with parents alone to help them to connect to, express, and work through their thoughts and feelings about their child's sexual orientation. These feelings often included loss, anger, fear, and shame. In addition, the authors found that it was often important to help parents: (1) reconcile their religious beliefs with their child's sexual orientation; (2) discuss and work through fears about disappointing, or being rejected by, their own family of origin or community; and (3) address their concerns for their child's welfare. Only after working through their own emotions were parents able to empathise with, and become more attentive to, their child's struggles with suicidal ideation or other forms of psychological distress. These parents were also able to attend to their child's attachment concerns and issues regarding sexual identity development and acceptance.

The authors also found that discussions about the meaning and process of 'acceptance' were important for both the adolescent and parents. For those adolescents who expected immediate and complete acceptance by their parents, reframing acceptance as an ongoing process reduced frustration and improved adolescent-parent interactions. Therapists validated the adolescent's justified demands for parental respect, validation, and safety, while also helping the adolescent recognise that it would take time for their parents to feel more comfortable with their sexual orientation. Results from a small open trial of this adapted version of ABFT showed that it was acceptable for this population and that, as a group, adolescents evidenced significant decreases in suicidal ideation, depressive symptoms, and maternal attachmentrelated anxiety and avoidance over the course of the treatment (Diamond et al., 2012).

This paper provides a case example from the aforementioned open trial to illustrate how the therapy was conducted with this population. We adopted an evidenced-based case study format. The case summary consists of a vignette, followed by task descriptions and illustrative transcripts. Examples of key therapeutic moments in ABFT for LGB adolescents are discussed in the context of the case. Dr Suzanne Levy was the therapist for this case. The family gave permission for use of their information with names and information changed to protect the identity of clients.

\section{Case Vignette}

Adela (16 years old) is a black, bisexual adolescent who lived with her mother, Edith, and younger siblings. The family was referred to the study from a local inpatient adolescent unit after Adela was hospitalised due to severe suicidal ideation and behaviours. At intake, Adela scored a 32 on the Suicide Ideation Questionnaire Junior (SIQ-JR - weekly version; Reynolds, 1988) and a 34 on the Beck Depression Inventory (BDI); Beck, Steer, \& Brown, 1996). Both of these scores are in the high clinical risk range. She also endorsed a 6.83 on the attachment-related avoidance subscale and a 4.25 on the attachment-related anxiety subscale of the Experiences in Close Relationships-Relationship scale (ECR-RS; Fraley et al., 2006), where 7 represents the most insecure range. 
Adela and her mother attributed her distress to a number of circumstances in her life. For instance, she had only intermittent contact with her father and thus felt abandoned by him. Adela also reported having difficulties with school and peers. Although very creative, athletic, and intelligent, Adela felt like she never fitted in with peers at school. This experience was exacerbated by having to 'start over' and make new friends every time they moved to a new city. The family underwent frequent moves as a result of Edith's prior military career and subsequent job changes. In addition, Adela reported that her mother had responded negatively to the disclosure of her bisexual identity. Her mother responded with criticism, shaming, high levels of anxiety, intrusive monitoring, and attempts to control her behaviour (e.g., block her from going out with her bisexual boyfriend). Adela not only felt hurt, but also discouraged from going to her mother for support, comfort, or advice to help cope with life's challenges.

Adela's mother, Edith, a first-generation immigrant from the Caribbean, brought her daughter to therapy because of concern for her daughter's suicidal ideation and depression, as well as her anger and susceptibility to 'peer pressure.' Edith reported a family history of mental health challenges, having herself experienced trauma and abuse as a child, and a history of domestic violence in her romantic relationships. She reported being unhappy about her daughter's sexual orientation, fearing it made her more vulnerable to discrimination and sexually transmitted diseases. Edith grew up in an extremely homophobic culture, where having an LGB identity was totally unacceptable, if not dangerous. At the time of treatment, Edith was taking college courses, raising not only Adela but her younger siblings, and working full-time. She was able to successfully manage her household and took great pride in her independence and self-sufficiency. She recently married her youngest child's father, with whom Adela got along well. Adela and Edith attended therapy sessions for 16 weeks.

\section{Task I - Relational Reframe}

The therapist began treatment by joining with Adela around her interests and strengths. Edith eagerly joined in, commenting on how good Adela was at softball, shopping, and art. She also commented on Adela's sophisticated sense of style. The conversation then moved to the problems fueling Adela's distress. Adela felt like she didn't fit in with her peers at school, missed her father, and was frustrated by her constant fighting with her mother. Adela felt that her mother was not accepting of her sexual orientation and that she consequently became over-controlling about her social life. Edith agreed that she worried about Adela's 'choice' of sexual orientation and feared it put her at risk for diseases and social ostracism.

After empathically exploring both Edith's and Adela's concerns, the therapist began the relational reframing process. The therapist asked Edith and Adela if Adela ever talked to her mother about the stressors in her life. When Adela said no, the therapist asked why. Adela said things usually ended with an argument; mum usually lectured and criticised her, which led her to feel frustrated and angry. Edith responded by blaming Adela, saying that it was her fault for not communicating more clearly.

At this point, the therapist diverted Edith and Adela away from attacking and defending and, instead, focused on the hurt and disappointment they were both feeling. The therapist asked both Adela and Edith if this is what happened at home that, instead of hearing each other and working through problems, they both ended 
up feeling frustrated and alone. The therapist reframed Edith's criticism and control as stemming from a deep love and concern for her daughter - a desire to protect her daughter. The therapist amplified mum's desire to help her daughter and empathised with her disappointment that her attempts at protection and closeness were not working. The therapist also reframed Adela's anger and withdrawal as reactions to her own disappointment at her mother's responses, and her depression and suicidal ideation as expressions of her hopelessness about the possibility of change. The reframe served to acknowledge both Edith's and Adela's frustration and anger, but focused them on their mutual sadness about their emotional distance, and their longing to connect. This shift made it possible to set relational repair as the initial focus of therapy.

Therapist: Look, I know things have been hard between you two. But if I could help your mother learn to listen to you better, be interested in what you are going through, and how you feel, instead of lecture or criticise, would you be interested in working on this?

Adolescent: She can't do that. I have tried in the past a million times and it always ends up in a fight.

Therapist: Was there was ever a time when you and mum were close?

Adolescent: Yes, in $9^{\text {th }}$ grade, before I came out to her as bisexual.

Mother: (with a tear in her eye) That is true. It used to be that she came to me about everything, she told me everything that was going on with her - when other girls were bothering her, whatever.

Therapist: Is that something that you both miss? That type of closeness?

Adolescent: (now also crying) Yes. Back then I just felt I could be myself with her. I just felt really happy.

Therapist: (to Edith) I can see how much you love your daughter, and how important the relationship is to both of you. If, somehow, I could help you two get some of that closeness back, help Adela to once again share with you what is going on with her, and help you make her feel heard and comforted, rather than have things escalate into arguments or fights, would you both want that; to feel together, instead of alone? To protect her without pushing her away?

Mother: Of course. That is what I am here for.

Therapist: Okay. That is what we will focus on initially in this therapy. I want to help Adela to do a better job of communicating, so that you don't have to guess what is going on with her and what she needs. And, I am going to help you respond in a way that makes her want to come to you to talk.

Although a bit reluctant, Adela agreed to the relational goal along with her mother. She wanted to feel loved by her mother again but she was doubtful that Edith could change. She did agree, however, to come to the next session and talk with the therapist about her reservations. The therapist ended the session by instilling some hope in the family by telling them, 'There is so much love here between the two of you. But it is buried under so much hurt. I'm confident that if you both put the work in, you can get that closeness back.' 


\section{Task I - Adolescent Alliance Building}

In the adolescent alliance building task (Task II), the therapist focuses on getting to know the adolescent better, understanding the depression, and discussing what gets in the way of talking to parents. If things go well, the therapist also prepares the adolescent to talk with his or her parents in the upcoming attachment task. With Adela, Task II consisted of four sessions.

The therapist started the task by getting to know Adela better, including her sexual identity development. The therapist explored Adela's experience realising she was bisexual, and her coming out process. Adela said it started in her pre-teen years, but that it was never upsetting. Her friends had always been accepting, but her family was always rejecting over her sexuality.

Next, the therapist explored Adela's depression and suicidal feelings. Adela described feeling abandoned by her father, fear related to witnessing domestic violence between her mother and her partners, and the pain and isolation caused by her mother's rejection of her as bisexual. The first three sessions of Task II focused on exploring these issues. The therapist listened to the story of these events and uncovered previously avoided painful emotions associated with them. Accessing these primary emotions (e.g., sadness, hurt, etc.), helped Adela better understand what drove her hopelessness and despair. It also helped her to put words to how her mother's dismissive and critical responses caused such pain and led her to withdraw. Legitimising these feelings also led her to realise her longing for her mother's acceptance (e.g., 'it sounds like, inside, you really want your mother to care and to be able to comfort you in a way that feels good'). If adolescents acknowledge and feel their pain and longing for attachment, the therapist can then offer therapy as an opportunity to heal that rupture.

In the following segment, the therapist helped Adela talk about her mother's responses to her sexuality, how these responses made her feel, and how they have undermined her trust in her mother.

Therapist: Let's talk about your sexuality. I know that has been a source of tension between you and your mother. When you told your mum that you were bisexual, that didn't go over so well?

Adolescent: It wasn't really that I told her, it was like ... I was talking to a girl, like, we weren't really going out, but we were like flirting with each other or whatever. And, I don't know how but I was asleep and my mother woke me up and she was like ... um, I guess I don't know my phone rang or something or she texted me or something, and she just started yelling and she was like ... I was half asleep so I don't really remember, I just remember she called me a lesbian and I was like, I'm not a lesbian because I like boys and she was like, but you like girls and I was like yeah, but I'm not a lesbian though. And then the next day she wouldn't even talk to me. She wouldn't even look at me.

Therapist: Mm. That sounds really upsetting. What was that like for you?

Adolescent: (said with despair) I was like, um, I mean I really felt like oh, she's probably going to send me away now.

Therapist: You sound sad. 
Adolescent: It's what I expected. That's why I didn't tell her. When we lived in California and we were sitting in a restaurant by a window it was me, her, and my aunt and these two girls got out of a truck. One of them was dressed kind of boyish and they were obviously a couple. And my mum was like, if you ever became a lesbian, no one is going to love you. Maybe she was joking. I really don't know. But I mean, I was like, if I told her, she's going to hate me. And then when she did find out, she stopped talking to me for like two days. I'm like ... this is exactly what I expected.

Therapist: Wow that sounds horrible. I wonder if you felt rejected by her, sort of abandoned by her because of who you are?

Adolescent: Yeah, that is right. Like she abandoned me. She wouldn't even look at me.

Therapist: That must have been awful.

Adolescent: It was awful, but that was just the start. She continues to make those sorts of comments [i.e., homophobic] to this day.

Therapist: What is that like for you?

Adolescent: It's awful. She doesn't accept me for who I am.

Therapist: It's almost like she's rejected who you are.

Adolescent: That's exactly it.

The therapist wanted Adela to connect with some primary emotions related to these stories and used her coming out story to get her connected to her pain. The therapist then helped Adela discuss the ongoing rejection and abandonment from her mother. The therapist also used attachment words like 'abandonment' and 'rejection' to help Adela understand how these relational ruptures contributed to her anger, hopelessness, and suicidal feelings. This helped Adela have a more coherent understanding of her experience, her emotions, and her distrust of her mother.

Adela went on to talk about feeling rejected by her father and grandmother. Both dismissed her bisexuality merely as peer pressure from her friends. Adela also angrily described how her mother would make fun of gay people and how she yelled and cursed at Adela when she caught her talking to girls. Given her mother's homophobia, Adela just stopped bringing LGB friends home. As the conversation continued, Adela felt a deeper sadness, but also an assertive anger - more entitled and empowered rather than passive and suicidal. Adela knew she deserved to be loved by her family regardless of her sexual orientation.

Therapist: (noticing that Adela is getting emotional) What is going on right now inside?

Adolescent: I feel like she doesn't like that part of me, she would like it better if I were straight. But yeah, I am not, so whatever.

Therapist: So she says that to you. What does it feel like when she says that?

Adolescent: I get so irritated, I'm like, I'm not going to be straight. You can say it all you want but I'm not ever gonna be straight again. 
Therapist: I can imagine that made you angry.

Adolescent: Yeah. I mean, I feel like she's dealing with me being bisexual now. Like we're trying stuff like this [therapy] ...W We've never talked, and then one time ... she started on this big thing and she was yelling at me and cursing and she called me a lesbian slut. I'm like 'I'm not a lesbian' and she's like 'You like girls, you're a lesbian.' She said she was watching Dr. Phil, and he said there's no such thing as bisexuals, it's just lesbians and straight. I'm like 'No, I like both, I'm bi, that's how it is.' She's like 'No you're a lesbian.'

Therapist: You know, that is really unfair.

Adolescent: Yeah.

Therapist: What worries me is that when you feel criticised by your mum and she devalues your bisexuality, it makes your suicidal thoughts worse.

Adolescent: (sighs and looks around) This is so much of who I am but she like, she's so much against it. She knows that it's a big part of who I am, a huge part. I feel like she's so against it, like she's trying to keep me from being who I am. It's almost like she's suffocating me, like pushing me in this box that I don't fit into. It is just not fair.

Adela went on to discuss how her mother's rejection of her bisexuality made her feel alone, angry, rejected, and helpless. Unlike some other sexual minority adolescents, she did not report feeling shame or guilt. Adela reported feeling pride in her identity, and that she had a network of support, including a strong community of bisexual individuals she knew outside of school. This made it all the more upsetting that her mother could not accept her. She was bisexual and wanted her mother's recognition and support. She also wanted a mother she could talk to about romantic and peer issues.

The therapist seized on this critical moment where Adela expressed both indignation and longing. Rather than turn to suicide, the therapist encouraged Adela to try and work this through with her mother. The therapist also reinforced the importance of directly expressing her hurt, disappointment, and desire to have her mother's support as opposed to yelling and screaming out of anger. Sharing these feelings directly with her mother would be her best chance at helping Edith understand the bind she puts her, Adela, in (e.g., 'I will only love you if you are straight!'). Finally, the therapist emphasised that this is also the best chance for Adela to convey to her mother the long-term consequences of this criticism and non-acceptance.

Adolescent: I mean I feel like ... if she doesn't accept that part of me like, all this therapy is almost pointless because this is who I am, and if you're going to be criticising me my whole life because of this, then how are we going to have a relationship? When I get older and I find someone and maybe you know I end up with a girl, and maybe if it's legal and we decide to get married, how am I supposed to invite her to my wedding if she won't accept that part of me?

Therapist: That is important feedback to give to your mother. She needs to understand that this part of you is not going away. If she can't love that part of you then that's really going to get in the way of your relationship. This might be gradual. Some things however have to change today. She has to stop this derogatory, critical 
tone. If she wants a relationship with you, which I think she does, she has to stop that right away. But other things like her feeling comfortable with you having a girlfriend or seeing you with a girlfriend might take more time and happen gradually. Just think, it took a little time for you to be comfortable with your sexuality, it may take her time as well. How do you feel about giving her some time to get more comfortable?

In this exchange, the therapist does a number of important interventions. The therapist differentiates between mother's non-acceptance and mother's hurtful behaviour, and supports Adela's right to not be verbally abused and to assertively set some boundaries with her mother. Adela's right to be protected and safe is immediate and non-negotiable if her mother wants a relationship. At the same time, the therapist shows empathy for the mother's struggles and accepts that she may not be able to fully accept, let alone affirm, Adela's sexuality in the immediate future. The therapist tries to help find a middle ground that can help mother and daughter begin to build trust again.

Compared to the typical course of ABFT for depressed and suicidal adolescents, Task II sessions are often extended for LGB adolescents given the complexity of the issues. As demonstrated in the segments above, the therapist consistently validated the adolescent's sense of rejection and betrayal by her mother and her right to be protected from criticism. At the same time, the therapist helped Adela to connect with underlying primary emotions and unmet attachment needs, and moved her toward change behaviour (i.e., talking to her mum). The therapist served as a secure base for Adela throughout this process, which helped Adela find the strength and courage to speak to her mother.

In the remaining Task II session, the therapist prepared Adela for the upcoming conversation; what she wanted to say, how she wanted to say it, and how to react if her mother was negative or non-responsive. The therapist assured Adela that she would not initiate conjoint sessions until she was sure that her mother was willing and able to listen better, and that Adela's welfare was foremost on the list of her mother's concerns.

\section{Task III - Parent Alliance Building}

The parent alliance building task (Task III) first helps parents understand how current stressors and their own attachment history influence their parenting. Therapists use this as leverage to activate parental caregiving instincts, thus motivating them to learn some new attachment-promoting parenting skills. Once parents are motivated, the therapist prepares them to use emotion-coaching skills to help their adolescent fully share their experience during the subsequent attachment task. With non-accepting parents of LGB adolescents, this often takes more time than working with parents of heterosexual teens. Part of the work requires uncovering layers of shame, loss, guilt, uncertainty, and fear about their child's sexual identity.

In this case, exploring how Edith's own history of trauma impacted upon her parenting was crucial. As a child, she was neglected and physically abused while living with extended family before coming to the United States in middle childhood. As an adult, she was the victim of domestic violence from a romantic partner. Given these experiences, themes of safety were at the forefront of her concerns for Adela. 
Preoccupied with keeping her daughter physically safe, Edith did not attend well to Adela's emotional needs. Moreover, growing up in the Caribbean, Edith internalised the homophobic and intolerant views her culture held toward same-sex attraction and behaviour. In her hometown, people who were 'out' were often attacked, or worse. When Edith found out that Adela was bisexual, this reactivated those attitudes and fears. She also assumed that bisexual people have multiple romantic partners simultaneously and practice unsafe sex. Thus, Edith became quite concerned about sexually transmitted diseases and other medical problems, worrying that Adela's current bisexual boyfriend (Eddie) was likely promiscuous and could potentially infect Adela. The therapist began to help Edith specify and differentiate between her various concerns about Adela's sexuality. Helping parents move from talking about sexual orientation in global terms to talking about specific aspects, implications, and fears often results in parents recognising that their catastrophic fantasies are not necessarily reality-based.

Edith also expressed her doubt that bisexuality was even real. Many parents seem confused or skeptical about the validity, stability, or causality of their child's sexual orientation, particularly a bisexual orientation. In part, we take a psycho-educational approach to this challenge, but we also encourage parents and adolescents to explore these topics in conversation together during the repairing attachment task. For example, we encourage parents to ask their adolescent when they became aware of their same-sex attraction, how they felt during that time, when they first told someone, what went on inside when they were keeping it a secret, and types of discrimination or victimisation they may have experienced. We coach parents to enter this conversation with curiosity and openness, and not with disbelief and defensiveness. In this case, as we often do, the therapist also referred Edith to local PFLAG meetings.

In the next stage of the task, the therapist explored with Edith how her non-acceptance of Adela's sexual orientation affected her parenting. Edith acknowledged that she often criticised her daughter and tried to dissuade her from pursuing a bisexual lifestyle. The therapist invited Edith to contemplate how her criticism impacted Adela. The therapist reminded Edith how she felt when she was ridiculed while being abused as a child. Drawing the parallel between Edith's experience as a child, and Adela's current experience, helped Edith to finally understand how her words were hurting Adela. Realising this, Edith became sad, helpless, and more empathic toward her daughter.

Mother: Where is my choice in this?

Therapist: You mean having to accept her sexual interests?

Mother: Right. Like it is an ultimatum. Why can't she just accept the fact that I don't like it. Why am I being forced to like it?

Therapist: I think that it is hard for many parents. I want to be absolutely clear this isn't about getting you to 'like it.' You have a lot of feelings inside. Fear, disappointment, loss, and perhaps even disgust (mother nods in agreement, beginning to tear up). I don't think these feelings are going to go away immediately and it will take a while for you to feel more comfortable with this part of Adela. I think it is okay to say that it is hard for you and that it will take time. The important thing is to let her know that you think she is okay and that you love her. That you are working on being more supportive, closer, and that you are committed to at least not hurting her in the meantime. 
Mother: And in the end, if it doesn't work out in her favour, if I try and I still really can't ... (sniffles) am I gonna be just sitting back waiting for her again?

Therapist: I think that just coming here, talking about this, showing you care, facing these feelings - all of that already is an act of love and commitment. I don't know how far you will be able to go - how comfortable with Adela's bisexuality and accepting you will become or whether the two of you will ever be able to become as close as you once were. I do know that, through our work together, I hope you both will remember that you need each other. Your criticism and her suicidal despair have to stop. Even if all that happens in the course of our work is that you protect her more, that is meaningful.

Mother: We just ... never ... we don't talk about it.

Therapist: I understand that and that will be part of our work. It is okay that you feel discomfort, sadness, loss, etc. And I think that that's a really honest thing. I think that it is okay to say to her...'Here is where I am at.' I do not want you to lie to her and say you are okay with this when you are not. You just need to tell her that you are willing to work on it. That is the starting point. All you can promise is that you will try and you will not humiliate or criticise her ... What do you think about that?

Mother: I am willing to try ... I'll give it a shot if it helps. It's tough.

Therapist: Yeah, it is tough.

Mother: It's painful.

Therapist: Yeah, and it's hard to be honest about it 'cause I know that you love your daughter so much. But I also know that you came into this world with your own values, and your hopes and your dreams for her. And it's okay to be sad that those things might not necessarily happen, or they might not look the way you want them to. And it takes time to adjust to that ...

In this segment, the therapist validated Edith's feelings of loss, disgust, pain, etc., and gave her permission to have the time to change. This often frees up parents to say things out loud that they have not permitted themselves to say privately. The therapist also helped Edith make the distinction between accepting and liking. Finally, the therapist made the distinction between not liking her daughter's sexual orientation and acting hurtfully toward her daughter because of her sexual orientation.

As Edith came into contact with her loss, pain, etc., she began to mourn. Through this mourning process, the therapist empathised with Edith, but also challenged some of her misconceptions (e.g., 'My daughter will never have a wedding'). In the following session, the therapist successfully prepared Edith to listen to her daughter.

Task III was not a linear process for Edith. The therapist and Edith worked through deep reaching fears, disappointments, and losses she was holding onto. Each of these had to be explored, validated, and processed. In addition, Edith's many misconceptions had to be examined and re-evaluated in order for her to move forward. Most importantly, Edith was released from the expectation that she needed to immediately and completely feel comfortable with her daughter's sexuality in order to be empathic to her child's needs and pain. 


\section{Task IV - Repairing Attachment}

The goal of the attachment task (Task IV) is to help the family have a corrective attachment experience: the adolescent brings up difficult emotional problems related to the parents and parents provide comfort, protection, and sensitivity. In the following segment, Adela discussed her past fear of coming out to her mother.

Adolescent: Um, I'm not sure where to start.

Therapist: I think there's a couple of entry points ... maybe we should start at the beginning ... when your mum found out you were bisexual.

Adolescent: That was really hard for me. When you first found out, ... it hurt a lot because you wouldn't even look at me or talk to me. This is what I had always feared you would do, I mean, like, we've never really talked about it. It's almost like it didn't even happen. Which hurt too because it's like, it's almost like you're ignoring that part of me.

Mother: First I want to say that I'm here for you and I'm sorry I hurt you. It was hurtful to me and I didn't know how to deal with it. I grew up with not knowing how to confront situations and not knowing how to deal with them immediately. That's why I've always told you, give me time, give me a day or two, don't I always say that? Let me know ahead of time.

Therapist: I think that what you're saying is great, but I'm wondering maybe before we go into your side of things, because I know that you have a lot to say to Adela. But maybe, Edith, you can find out a little bit more, of what it was like for her to have kept it from you.

The therapist stopped Edith here and acknowledged her apology. Edith was trying to engage positively, but she had not yet given her daughter the opportunity to fully express her thoughts, feelings, and memories. The goal was to help Adela speak about her experiences in as complete a manner as possible, while Edith focused on understanding her daughter. In this way, while the family is working through relational disappointments, Adela is also working through her internal construction of what happened and how she felt. Given the freedom to explore this story and avoiding emotions helps adolescents develop a more coherent and emotionally integrated understanding of themselves and their relationships.

Adolescent: I mean, I didn't want to. like. hide it, but I was scared about how you were gonna react. I mean I wanted to tell you because I felt like, you're my mum, so stuff like that I should be able to tell you. I didn't feel like I could. And it's like, I was just scared ... about how you were gonna react because I mean ... I knew you didn't really, like, approve of that kind of thing but, so um ...

Mother: I'm trying, because I love you and you mean the world to me ... Who I am today is a total different person. I'm still me, but my maturity level, um, I handle things completely different. Yes, I used to blow up before and that's exactly what happened. I found out in a not good way, you didn't come to me and tell me and I found out, and that was my reaction. And I know I haven't had good reactions since then, but I'm going to do all that I can to support you and to learn more about it ... I don't know what else to do but support you. 
Adolescent: That's all I want. That's all you can do anyways, that's all I wanted.

Therapist: You know Adela, I can see that mum's response is really meaningful to you and I think mum is being really brave and taking responsibility and apologising. I am also impressed by how understanding you are. I was wondering, though, if there was something mum could do in the meantime as you worked through all of this together to help you feel better. You know, you talked about the negative comments. Tell your mum what it has been like to hear her call you names.

Adolescent: It's been horrible mum. It's made me feel all alone and rejected by you.

Mother: I understand how hurtful that is been. I'm sorry. It is hard for me. I still can't watch you and another girl together without cringing. Right now, I am not going to lie. I wish you were just like any other girl, but I understand how my words are hurtful. I will stop that. And if I slip, you can tell me. I want you to tell me so that I don't do that anymore.

Over the next few weeks, Adela had a growing sense that mum was genuine in her intentions and had started to change. In fact, at one point, Edith asked Adela if she could wear Adela's pride bracelet between sessions. During subsequent conjoint attachment sessions, the conversations seemed to flow more easily and, as trust and intimacy increased, new challenges were explored. Adela talked with her mother about witnessing Edith's domestic violence and her resentment about the frequent moving. Adela also talked more directly about how her mother shamed and humiliated her. Edith remained non-defensive and empathic, inviting Adela to share her feelings, asking questions, and trying to understand. These conversations clearly brought relief and a sense of closeness to them both. Although no conversation could actually change the events of the past, Adela no longer experienced feeling rejected by her mother. Both Adela and Edith felt they could move forward with more connection and better communication.

\section{Task V - Promoting Autonomy}

The family only needed three conjoint attachment sessions before moving on to promoting autonomy sessions (Task V). Task V shifts away from an explicit focus on ruptures in the relationships and more onto challenges in the adolescent's life, with the parent serving as a secure base of support. Topics focused on discussing plans for the future (i.e., school, relationships, sex, and involvement in the LGBTQIA community) and Adela's father's disengagement. Throughout these conversations, Edith and Adela used their new skills and new-found trust to speak about these issues in a more open and mutually validating manner. Instead of becoming dismissive and defensive, Edith would listen openly to her daughter's experiences and perspectives. As a result, Adela stayed engaged in the conversation and was honest and emotionally regulated. The more Adela was honest with her mum, the more Edith could trust her. Additionally, the more Edith and Adela discussed Adela's sexuality honestly, the more accepting Edith became of Adela's bisexual identity. The following segment is an example of how Adela and Edith began to handle the difficult issues surrounding Adela's sexuality.

Mother: She didn't know but I didn't sleep last night because I'm worried about her making the right decisions when it comes to Eddie [the bisexual boyfriend] because 
you're not opening up to me so I don't know, I'm scared that you're not going to come to me when you get to that point [having intercourse] and you feel that you and Eddie want to take the next step.

Adolescent: I guess I was thinking about the same thing when I was going to sleep. If it came to that point, would I be able to tell you about it and like ... how I would want to ... and I'd be scared to and I would just, like I don't know because it's so weird ... I can't. I wouldn't be able to anticipate what you would say and I was thinking about it right before I was sleeping.

Therapist: What were you worried she would say?

Adolescent: I don't know - that's the problem. I didn't know what to expect. That's the scary part.

Therapist: So why don't you ask her now?

Adolescent: Like if I did decide to tell you I'm going to have sex with him, I have no idea what you would say, and that is scarier than actually saying it.

Mother: What I would say is that number one it's your decision and number two, are you ready? And if you are, you need to get protection. I need to get you protection.

Adolescent: So you wouldn't tell me not to do it?

Mother: No, I'm not going to say that because I know how I felt about being with someone when I was your age, I wanted to be with someone, and I know that I had those strong feelings. It was just unfortunate that I had to go up there and learn on my own. I couldn't talk to my mum about this stuff.

Adolescent: I thought you were gonna like get mad, I don't know why but that's kinda what I was expecting.

Mother: I also have another question, not another question but a concern because I didn't have the choice to make the decision 'was I ready or not.' Do you want to do this now in your life or do you want to wait and see? Like maybe, you know, if you're gonna find somebody that you're really in love with? Or are you really in love with Eddie? Do you think that the relationship is gonna last for a while? Do you look to the future for you and Eddie? Do you want it to be just something casual? There's a lot of questions, there's a lot of questions that you have to think about before you do it.

Adolescent: Yeah I know, I actually think about that a lot, whether me and him are gonna last that long and I don't know. For no particular reason I feel like we are.

Edith and Adela continued to discuss relationships and qualities to look for in a partner. Edith was less preoccupied with her daughter's sexual identity, which opened space for her to have conversations about sex, love, commitment, and contraception. Edith was impressed with how thoughtful her daughter had been, making her feel comfortable granting Adela more psychological and behavioural autonomy. Given mum's history of domestic violence, themes of protection and safety came up repeatedly throughout therapy. However, as a result of the new trust between Edith and 
Adela, Adela no longer experienced her mother's questions as a lack of trust, but rather as an act of love.

Through the use of ABFT for LGB suicidal youth, Edith and Adela's relationship was transformed by the end of therapy. While Edith was still working on her process of acceptance regarding Adela's sexuality, she was no longer insulting or criticising her daughter. Additionally, Edith was taking measures to understand bisexuality and cope with her own homophobia and fears. Since Adela no longer felt rejected and criticised by her mother, she was able to use her mother as a secure base so that she could further explore her autonomy.

\section{Case Review}

This case represents a successful therapeutic course of ABFT, where issues of sexual identity were at the forefront of the relational ruptures. By the end of the therapy, the adolescent's suicidal ideation decreased from 32 (clinical level) to 4 (below normative level) on the Suicide Ideation Questionnaire - Jr. While Adela's depressive symptoms remained elevated, they decreased from a 34 to a 25 on the Beck Depression Inventory. Additionally, her attachment-related avoidance and anxiety toward her mother had reduced from an ECR Avoidance score of 6.83 at intake, to 2.50 at posttreatment; and from an ECR Anxiety score of 4.25 at intake, to 1.25 at post-treatment. Parent-child communication was also improved.

This case reflects some of the essential components of ABFT for depressed and suicidal LGB adolescents. The particular themes and obstacles toward acceptance and reconnection, however, will vary from case to case. For some parents, the therapy may revolve around their shame and fear of what others in their family and community might say. For other parents, substantial time and conversation might be devoted to helping parents ask about and hear their child's experience of coming out to themselves, in order to help them come to terms with their child's LGB identity. In all cases, however, the thrust of the work involves identifying how disengagement, criticism, shame, fear, and anger, associated with parental non-acceptance, have compromised the parent-child relationship and the child's well-being. Furthermore, working to establish safety, mutual respect, and intimacy restores security in the relationship.

\section{Acknowledgment}

This paper was supported by a grant from the American Foundation for Suicide Prevention.

\section{References}

Beck, A.T., Steer, R.A., \& Brown, G.K. (1996). Manual for the Beck Depression Inventory-II. San Antonio, TX: Psychological Corporation.

D’Augelli, A.R., Grossman, A.H., Starks, M.T., \& Sinclair, K.O. (2010). Factors associated with parents' knowledge of gay, lesbian, and bisexual youths' sexual orientation. Journal of GLBT Family Studies, 6(2), 178-198.

Diamond, G.M., Diamond, G.S., Levy, S., Closs, C., Ladipo, T., \& Siqueland, L. (2012). Attachment-based family therapy for suicidal lesbian, gay, and bisexual adolescents: A 
treatment development study and open trial with preliminary findings. Psychotherapy, 49 (1), 62-71. doi:10.1037/a0026247.

Diamond, G.S., Diamond, G.M., \& Levy, S.A. (2014). Attachment Based Family Therapy for Depressed Adolescents. Washington D.C: American Psychological Association.

Eisenberg, M.E., \& Resnick, M.D. (2006). Suicidality among gay, lesbian and bisexual youth: The role of protective factors. Journal of Adolescent Health, 39(5), 662-668.

Evans, E., Hawton, K., \& Rodham, K. (2004). Factors associated with suicidal phenomena in adolescents: A systematic review of population-based studies. Clinical Psychology Review, 24, 957-979.

Fraley, R.C., Niedenthal, P.M., Marks, M.J., Brumbaugh, C.C., \& Vicary, A. (2006). Adult attachment and the perception of emotional expressions: Probing the hyperactivating strategies underlying anxious attachment. Journal of Personality, 74, 1163-1190.

Goldfried, M.R., \& Goldfried, A.P. (2001). The importance of parental support in the lives of gay, lesbian, and bisexual individuals. Journal of Clinical Psychology, 57(5), 681-693.

Haas, A., Eliason, M., Mays, V., Mathy, R., Cochran, S., D’Angelli, A., \& Clayton, P. (2011). Suicide and suicide risk in lesbian, gay, bisexual, and transgender populations: Review and recommendations. Journal of Homosexuality, 58(1), 10-51.

Hammelman, T.L. (1993). Gay and lesbian youth: Contributing factors to serious attempts or considerations of suicide. Journal of Gay and Lesbian Psychotherapy, 2, 77-89.

Heatherington, L., \& Lavner, J. (2008). Coming to terms with coming out: Review and recommendations for family systems-focused research. Journal of Family Psychology, 22, 329-343.

Hunter, J., \& Schaecher, R. (1987). Stresses on gay and lesbian adolescents in schools. Social Work in Education, 9(3), 180-189.

Marshal, M.P., Dietz, L.J., Friedman, M.S., Stall, R., Smith, H., McGinley, J., ... Brent, D. A. (2011). Suicidality and Depression Disparities between Sexual Minority and Heterosexual Youth: A Meta-Analytic Review. The Journal of Adolescent Health : Official Publication of the Society for Adolescent Medicine, 49(2), 115-123. http://doi.org/10.1016/j.jadohealth.2011. 02.005

Nadal, K.L., Issa, M., Leon, J., Meterko, V., Wideman, M., \& Wong, Y. (2011). Sexual orientation microaggressions: 'Death by a thousand cuts' for lesbian, gay, and bisexual youth. Journal of LGBT Youth, 8(3), 1-26.

Needham, B.L., \& Austin, E.L. (2010). Sexual orientation, parental support, and health during the transition to young adulthood. Journal of Youth and Adolescence, 39, 1189-1198.

Reynolds, W.M. (1988). Suicidal Ideation Questionnaire: Professional Manual. Odessa, FL: Psychological Assessment Resources.

Robinson, B.E., Walters, L.H., \& Skeen, P. (1989). Response of parents to learning that their child is homosexual and concern over AIDS: A national study. Journal of Homosexuality, 18 (1-2), 59-80.

Rohner, R.P. (2014). Parental power and prestige moderate the relationship between perceived parental acceptance and offspring's psychological adjustment: Introduction to the International Father Acceptance-Rejection Project. Cross-Cultural Research, 48, 197-213. doi:10.1177/1069397114528295.

Ryan, C., Russell, S.T., Huebner, D., Diaz, R., \& Sanchez, J. (2010). Family acceptance in adolescence and the health of LGBT young adults. Journal of Child and Adolescent Psychiatric Nursing, 23(4), 205-213.

Samarova, V., Shilo, G., \& Diamond, G. (2014). Changes in youth's perceived parental acceptance of their sexual minority status over time. Journal of Research on Adolescence, 24(4), 681-688. doi:10.1111/jora.2014.24. 
Savin-Williams, R.C. (1989). Coming out to parents and self-esteem among gay and lesbian youths. Journal of Homosexuality, 18(1-2), 1-35.

Savin-Williams, R.C. (1994). Verbal and physical abuse as stressors in the lives of lesbian, gay male, and bisexual youths: Associations with school problems, running away, substance abuse, prostitution, and suicide. Journal of Consulting and Clinical Psychology, 62(2), 261269. doi:10.1037/0022-006X.62.2.261.

Savin-Williams, R.C. (2006). Who's gay? Does it matter? Current Directions in Psychological Science, 15(1), 40-44.

Savin-Williams, R.C., \& Ream, G.L. (2003). Suicide attempts among sexual-minority male youth. Journal of Clinical Child and Adolescent Psychology, 32(4), 509-522.

Shilo, G., Antebi, N., \& Mor, Z. (2015). Individual and community resilience factors among lesbian, gay, bisexual, queer and questioning youth and adults in Israel. American Journal of Community Psychology, 55(1-2), 215-227. doi:10.1007/s10464-014-9693-8.

Sue, D.W., Capodilupo, C.M., Torino, G.C., Bucceri, J.M., Holder, A.M.B., Nadal, K.L., \& Esquilin, M. (2007). Racial microaggressions in everyday life: Implications for clinical practice. American Psychologist, 62(4), 271-286. doi:10.1037/0003-066X.62.4.271. 